\title{
Young Carers, The Overlooked Caregiving Population: Introduction to a Special Issue
}

\author{
Melinda S. Kavanaugh ${ }^{1} \cdot$ Vivian Stamatopoulos $^{2}$
}

Accepted: 1 September 2021 / Published online: 13 September 2021

(c) The Author(s), under exclusive licence to Springer Science+Business Media, LLC, part of Springer Nature 2021

\begin{abstract}
"Young carers", or "caregiving youth", have existed on the fringes of the caregiving literature, programming and support for decades, beginning the UK in the early 1990's (Leu $\&$ Becker, 2017), which has informed over two decades of targeted young carer programs, services and funding. Yet, the overall inclusion of children and youth into the larger caregiving literature has lagged, often due to social norms or expectations as to what constitutes a "caregiver" and what is considered outside the social constructs of the role children and youth have in families.
\end{abstract}

Despite these considerations children and youth caregivers persist, as does the extensive care they provide, in relative obscurity. Their hidden nature is exacerbated by their being left outside most state caregiving policy in the developed world, particularly North America, where in the US, national caregiving policy begins at the age of 18 (Kavanaugh et al., 2015) or in Canada, where supports are connected to income tax credits geared towards working adults (Stamatopoulos, 2015). The lack of attention paid to young carers, particularly in North America, was confirmed by an updated global comparison of in-country awareness and policy responses to young carers (Leu \& Becker, 2017). Here, and as was the case in its preceding global typology (Becker, 2007), the United Kingdom retained its placement as the only "advanced" model of awareness, recognition and social service provisioning for young carers, with no country found to have a fully "incorporated/sustainable" set of legal rights and policy interventions to meet young carers' needs and promote their overall health, well-being and development (Leu \& Becker, 2017).

This special issue of Child and Adolescent Social Work Journal, addresses several of these issues, by drawing

Melinda S. Kavanaugh

kavanaug@uwm.edu

1 Helen Bader School of Social Welfare, University of Wisconsin-Milwaukee, Milwaukee, USA

2 Ontario Tech University, Oshawa, Canada attention to the lack of research on young carers around the globe, the broader conceptualization and enumeration of these young people, the development of programs and services to support them and their family members, and the unequal conditions of care that are connected to intersecting axes of discrimination, including but not limited to gender, race/ethnicity, sexuality, disability and class.

To start off the special issue, Hendricks, Kavanaugh $\&$ Bakitas (2021a) point to the overall lack of attention to young carers in their scoping review of primarily US young carer research. Building off an earlier 2015 scoping review conducted by Kavanaugh et al. (2015), which found a paltry 22 peer reviewed papers on young carers compared to the thousands of peer reviewed publications addressing adult caregivers, this updated review was only able to find an additional four publications over the ensuing 6 years. Indeed, very few questions poised in the initial review were answered given the small number of studies, including how caregiving varies by race/ethnicity and location. By underscoring the continued lack of attention and awareness paid to young carers in the US, often considered the leader of the developed world, this review re-affirms how far behind the US remains vis-a-vis the basic acknowledgement of the role children and youth play as caregivers, as well as the provision of care supports targeting their unique needs.

The second paper in the series provides an intersectional approach to the unequal conditions of care. In an ethnographic investigation of young carers and their families in the West Midlands (UK), Alexander (2021) highlights the need for an expanded emphasis on how supportive policies take on a different character (i.e. more or less supportive, more or less punitive) dependent on the social location of the young carer. By drawing on positions of privilege, including but not limited to class, 'race'/ethnicity and citizenship, Alexander reveals how important markers shape family circumstances and young carers' experiences within those families. By drawing our focus to the heterogeneity of experience and supports within the broader young carer 
community, this research draws our focus to how policies can seek to improve and/or alter the experiences of young carers whose often intersecting inequalities contribute to further marginalization of their care work and access to available supports.

Third in the series, we have Bernardi, Chalmers \& Heather's (2021) contribution highlighting the contradictions seen in adult caregivers - that of the ability to show compassion to others in the form of care, yet struggling with self-compassion. Young carers possessed high levels of compassion, yet were largely unable to feel self-compassion —or identify ways to care for themselves while also struggling to receive the same level of compassion from family members. Moreover, this problem was particularly pronounced among older young carers in the sample, where self-care was seen as a character flaw connected to selfishness and guilt for taking off time for self-care. By teasing out the contradiction whereby young carers are quick to help others before helping themselves, this study corroborated other research demonstrating the tendency of young carers, particularly older ones, to put the needs of others before their own.

Next up, Hendricks, Vo, Dionne-Odom \& Bakitas (2021b) put a much-needed spotlight on those caregiving dynamics marked by the concept of "parentification" whereby the young carer takes on of adult roles and responsibilities as either a feature of parental neglect but also parental illness or incapacitation. By teasing out how a lack of support from self and family may have to do with how caregiving is conceptualized, and whether the role of the young carer crosses over into "parenting" the ill parent, this paper teases out the differences and similarities between the young carer and parentification literatures, which for long have been kept separate due to a resistance by young carer scholars to apply the concept of parentification to the case of young carers (Frederick et al., 2020). Using the Rodgers' evolutionary method to amalgamate existing literature on parentification of young carers, the authors review 25 articles to then chart the antecedents, attributes and consequences of parentification among young carers. Their resulting framework provides a fruitful foundation for further research in this currently understudied area while helping to draw catered supports to parentified young carers in order to mitigate its more harmful consequences.

Whether the youth is parentified, or has a lack of support, what is exceedingly clear is the overall need for services for these young people, exemplified in Phelps' (2021) paper. The UK has one of the most robust and well established young carer programming in the world, with the majority delivered at the community level with the intent to provide localized and targeted services However, not all young carer families are actually receiving the services. In an evaluation of young carer programs in the Hampshire area UK, Phelps details not only the services needed by young carers and their families, but specifically how the provision of services impacted the well-being of the family as a whole. Results highlight the many ways in which young carers are supported by no longer feeling alone, having similar peers and opportunities for respite. While parents feel supported by having access to staff members who understand their situation, with the opportunity to build relationships with these staff. These data underscore the critical need for not only localized services, but those run by staff who are dedicated to support and engagement with young carers and their families. Sadly, these programs are not replicated across the globe, primarily due to cost and lack of a socialized care system, but most critically due to a lack of awareness and attention paid to the role of young carers.

Kettell's (2021) contribution extends the conversation around young carer service provisioning by addressing the absence of a validated tool or measure with which to identify such young people for potential programming. With this in mind, Kettell set out to develop a global screening tool for use with young carers of a family member with a progressive or long-term illness or disability. By working in a participatory fashion with young carers and health, social care and education professionals from the UK, USA and Canada, the resulting Carers' Alert Thermometer (CAT-YC) contains an identification question followed by 10 areas of need across two themes of 'current caring situation' and 'carer's health that can be used as a standardized assessment for young carers in any number of settings. Not only can this tool be used to identify the need for supports and appropriately triage young carers for said supports but it can also be used an empirical tool to help establish prevalence estimates in countries that do not nationally enumerate for the presence of informal caregiving among younger populations.

The final contribution in the series bring much of the above discussion together by seeking to assess how young carers feel about their experiences. Here, Hamill (2021) highlights her development of a new "Feelings About helping" scale to assess feelings of care among a US sample of high-school aged young carers providing care to grandparents. Results highlighted three primary factors, burden, meaning, and negative physiological responses-all critical to informing how support programs can be developed. Moreover, the focus on how youth feel about helping addresses two understudied areas, that of the physiological impacts of care and care provided by young people to older adults. However, what Hamill addresses is that youth are indeed affected physiologically and that we should be drawing more research focus on how our aging population will continue to draw more youth into grandparent caregiving roles.

The papers in this special issue are much needed in the advancement of not only the science of young carer research, but the development and delivery of support programs and services for a uniquely vulnerable, isolated, and understudied 
caregiving population. The hope for this edition is to not simply add to the literature, but to raise awareness for the broader need to include all caregivers, not merely adult caregivers, in local, national and international research and state policy agendas. It is imperative that we continue to elevate the voices of young carers to caregiving policy and make it widely known that they are a significant and growing caregiver cohort that requires our attention and support.

\section{References}

Alexander, C. (2021). Unequal conditions of care and the implications for social policies on young carers. Child and Adolescent Social Work Journal. https://doi.org/10.1007/s10560-021-00781-w

Becker, S. (2007). Global perspectives on children's unpaid caregiving in the family. Global Social Policy, 7(1), 23-50.

Bernardi, Y., Chalmers, H., \& Ramey, H. (2021). Unfolding what selfcompassion means in young carers' lives. Child and Adolescent Social Work Journal. https://doi.org/10.1007/s10560-021-00791-8

Frederick, T., Vitopoulos, N., Stamatopoulos, V., \& Kidd, A. S. (2020). Brief Report: Youth homelessness, youthful caregiving, and resilience. Journal of Child and Family Studies. https://doi.org/10. 1016/j.childyouth.2021.106177

Hamill, S. (2021). Assessing young caregivers' feelings about helping: pilot test of a new scale. Child and Adolescent Social Work Journal. https://doi.org/10.1007/s10560-021-00792-7

Hendricks, B., Kavanaugh, M. S., \& Bakitas, M. (2021a). How far have we come? An updated scoping review of young carers in the
U.S. Child and Adolescent Social Work Journal. https://doi.org/ 10.1007/s10560-021-00783-8

Hendricks, B., Vo, J., Dionne-Odom, J., \& Bakiatas, M. (2021b). Parentification among young carers: A concept analysis. Child and Adolescent Social Work Journal. https://doi.org/10.1007/ s10560-021-00784-7

Kavanaugh, M. S., Stamatopoulos, V., Cohen, D., \& Zhang, L. (2015). Unacknowledged caregivers: A scoping review of research on caregiving youth in the United States. Adolescent Research Review. https://doi.org/10.1007/s40894-015-0015-7

Kettell, L., O’Brien, M., Jack, B., \& Knighting, K. (2021). Development of the Carers' Alert Thermometer for Young Carers (CATYC) to identify and screen the support needs of young carers: a mixed method consensus study. Child and Adolescent Social Work Journal. https://doi.org/10.1186/s12904-015-0010-6

Leu, A., \& Becker, S. (2017). A cross-national and comparative classification of in-country awareness and policy responses to "young carers". Journal of Youth Studies, 20, 750-762.

Phelps, D. (2021). What changes for young carers? a qualitative evaluation of the impact of dedicated supportprovision for young carers. Child and Adolescent. Social Work Journal.

Stamatopoulos, V. (2015). One million and counting: The hidden army of young carers in Canada. Journal of Youth Studies, 18(6), 809-822.

Publisher's Note Springer Nature remains neutral with regard to jurisdictional claims in published maps and institutional affiliations. 